\title{
Comparing the Effect of Facial Compression Bandage to That of Systemic Dexamethasone on Postsurgical Sequels after Extraction of Impacted Mandibular Third Molars: A Split-mouth Randomized Clinical Trial
}

\author{
Ibraheem Hamadi ${ }^{1}$, Nuraldeen Maher Al-Khanati ${ }^{1,2 *}$ (D), Zafin Kara Beit ${ }^{1}$ (D) \\ ${ }^{1}$ Department of Oral and Maxillofacial Surgery, Faculty of Dental Medicine, Damascus University, Damascus, Syria; ${ }^{2}$ Department \\ of Oral and Maxillofacial Surgery, Faculty of Dentistry, Syrian Private University, Damascus, Syria
}

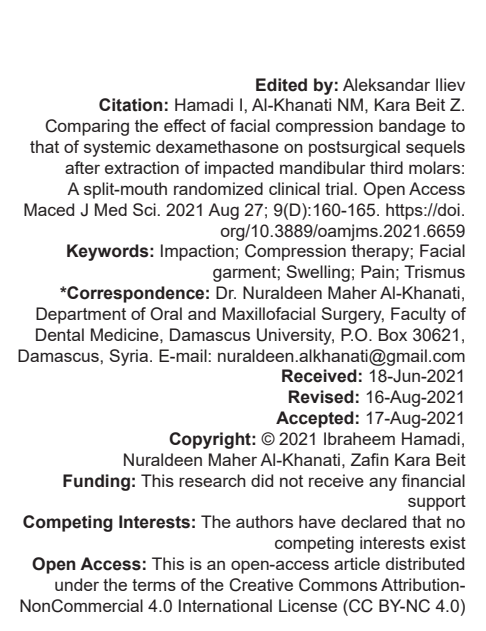

\begin{abstract}
AIM: The present study aimed to compare the clinical efficiency of facial pressure bandage, to that of intramuscular injection of dexamethasone $(8 \mathrm{mg}$ ) on postsurgical sequels (swelling, pain, and trismus) of extraction of impacted mandibular third molar

METHODS: The study implemented a randomized split-mouth design. Patients with symmetrical bilateral impacted molars were eligible for the present trial. Sides were randomly assigned to two groups: pressure bandage group and dexamethasone group. The evaluated postsurgical sequels were extraoral swelling, trismus, and pain after $48 \mathrm{~h}$ and 7 days.

RESULTS: The study included 42 impacted third molars $(n=42)$ in 21 patients with a mean age of 23.4 years. Most participants were females $(66.7 \%)$. The mean postoperative swelling rates after $48 \mathrm{~h}$ and 7 days in pressure bandage group were found to be comparable to those of dexamethasone group. No significant difference was found in the mean rates of postoperative trismus between study groups after $48 \mathrm{~h}$ and 7 days. Differences in mean pain level scores between the pressure bandage group and dexamethasone group were statistically insignificant after $48 \mathrm{~h}$ and 7 days.

CONCLUSION: The study findings showed that the effect of the pressure bandage was comparable to dexamethasone
\end{abstract} effect on the postsurgical sequels after surgical extraction of impacted mandibular third molars.

\section{Introduction}

Every oral surgery, including impacted third molar surgery, is followed by a group of expected postoperative symptoms or minor complications which are known as postsurgical sequels [1]. These mainly include facial swelling, pain, and trismus. Postsurgical sequels severity might vary tremendously depending on many factors, for example., surgical difficulty, procedural duration, trauma of soft and hard tissues, host response, and patient postsurgical instructions and medication [2], [3]. The use of systemic medications, i.e., non-steroidal anti-inflammatory drugs (NSAIDs) and corticosteroids, had been an omnipresent practice to prevent, reduce or manage those postsurgical sequels [4], [5]. Despite the effectiveness of these medications, they were not free of risks, adverse sideeffects, or toxicity in some patients [6], [7]. Emerging evidence that presents safer effective alternatives is recently the focus center of many studies [1], [8]. Hereby, the presented study aimed to compare the clinical efficiency of facial pressure bandage to intramuscular dexamethasone on impacted mandibular third molar postsurgical sequels, namely, swelling, pain, and trismus.

\section{Patients and Methods}

The patients were enrolled in this crossover randomized clinical controlled trial and managed according to a prospective study protocol. The research protocol was reviewed, and ethical approval was obtained by the Research Ethics Committee of Damascus University (Registration No. 20201396). Patients who attended the department of oral and maxillofacial surgery (Damascus University, Damascus, Syria) for surgical dental extractions in the period from September 2020 to March 2021 were included in the study. All participants provided 
detailed informed consent. Eligibility criteria included: (1) healthy non-smoking patients with asymptomatic, bilateral mesioangular impacted mandibular third molars; (2) patient age range between 18 and 40 years; (3) good oral health; (4) no recent history for systemic administration of NSAIDs or corticosteroids.

Presurgical assessment of surgical difficulty or potential complexity was done via Pernambuco index [9]. Cases with scores more than 12 points on that index had to be excluded from the study. In addition, exclusion criteria were: (1) uncontrolled diabetes; (2) poorly treated hypertension; (3) untreated infections; (4) pregnancy; (5) history of radiotherapy or chemotherapy; (6) active smoking of any type. Surgical difficulty was re-assessed immediately post-surgery on $10-\mathrm{cm}$ visual analog scale (VAS) by the operator.

Each impacted molar case was randomly assigned into one of the study groups (pressure bandage group versus intramuscular dexamethasone group) using computer-generated random number table. The crossover study design allowed each participant (with two eligible impacted third molars) to be included twice in both groups with a washout period between the two surgeries of at least 3 weeks. Baseline clinical measurements before each surgery included facial measurements to assess facial swelling level. The measurements were performed by measuring the linear distances between three anatomical reference points, namely the distance from oral commissure to tragus (OC-T) and from oral commissure to mandibular angle (OC-A). Indelible ink was used to identify these landmarks, and with the aid of silk tape, the measurements were made. Baseline measurements also included maximum mouth opening by measuring the interincisal distance. Pain level was recorded on a 10-cm VAS with a score ranging from 0 (pain-free) to 10 (worst possible pain). Baseline presurgical pain score of more than 0 had to postpone the following procedures until the patient returned into the state-of-zero pain level.

All surgical extractions were performed by the same oral surgeon and the same assisting team. The exact same surgical technique was applied for both sides in every patient. Extraction of mandibular third molars was completed under local anesthesia of $2 \%$ lidocaine with 1:80,000 epinephrine. Next, a buccalbased triangular flap, with modified Ward's incision, was raised [8]. In order to expose the impacted tooth crown, ostectomy was done via surgical carbide round bur on a straight surgical handpiece $(25,000 \mathrm{rpm})$ with copious external saline irrigation. All cases were done without the need for teeth sectioning before extraction. Eventually, the flap was sutured with $4 / 0$ silk suture to allow primary wound healing to take place. Two durations were recorded (in minutes) using timekeepers. Total surgical duration was defined as the time spent to complete the surgery, starting from the incision to the last knotted stitch. Time particularly taken to expose the crown through requisite bone removal was also recorded.
After the surgical procedure, all study participants received the same post-extraction instructions regarding local hemostasis, oral hygiene, food, and drinks. Post-operative medications included the same oral analgesic (paracetamol $500 \mathrm{mg}$, as needed) and mouthwash $(0.12 \%$ chlorhexidine solution, swish, and spit, twice/day) for the two study groups. Participants were asked to record the number of painkiller tablets taken each day post-surgery to assess patient need for analgesic. In the test group, no additional medications were prescribed postoperatively, but a facial pressure bandage (Variteks Orthopedics Industry Inc; Zeytinburnu, Istanbul, Turkey) was applied on the patient's face (Figure 1). After selecting and applying the suitable size according to manufacturer instructions based on patient's neck circumference, the facial compression bandage was supported on the surgical side of the face with $10 \mathrm{~cm} \times 10 \mathrm{~cm}$ gauze pad underneath to ensure it was tight enough there. Participants were instructed to exercise their jaw by repeated gentle mouth opening and closure, alongside with lateral mandibular movements for 20 min after compression bandage application. Operator asked the patients to repeat these gentle exercises multiple times during the next $48 \mathrm{~h}$, and not to unclothe the bandage by themselves even while sleeping. The patient face was unbandaged after $48 \mathrm{~h}$. Participants assigned to the control group received an immediate single-dose intramuscular dexamethasone $(8 \mathrm{mg})$ instead.

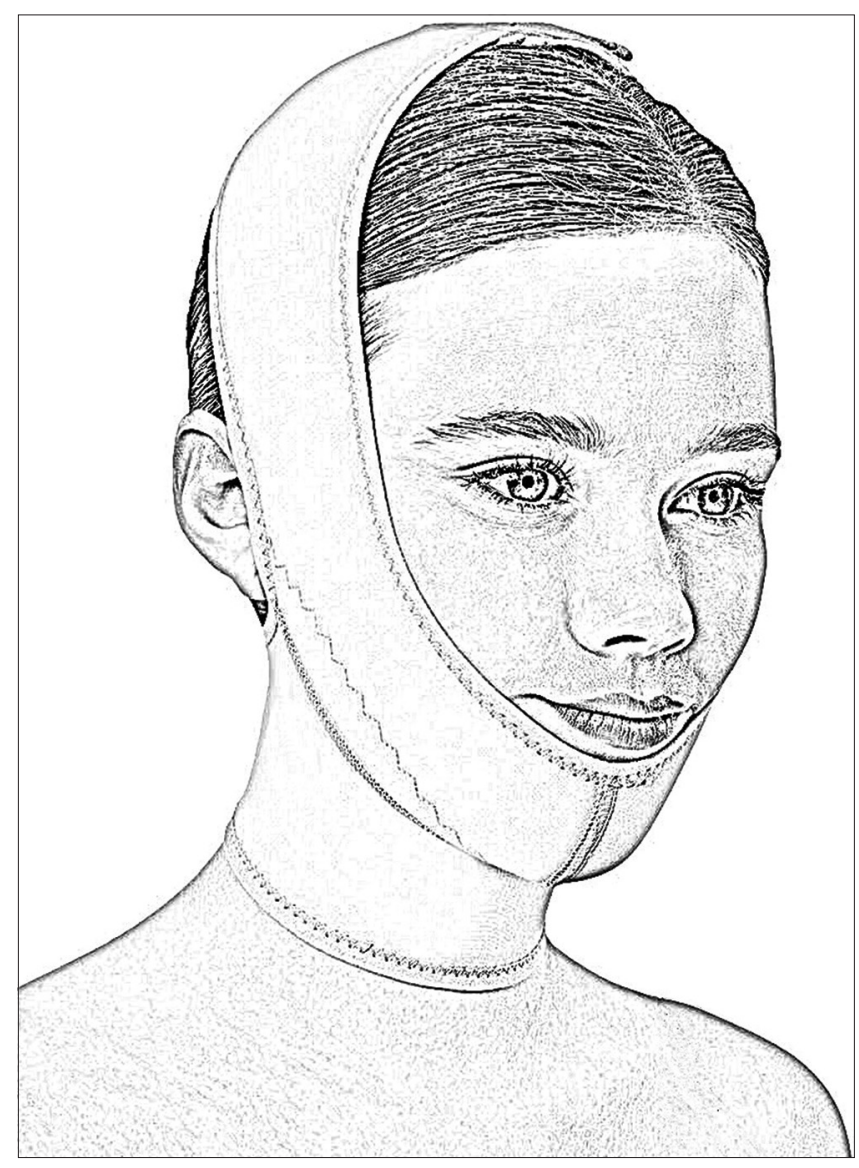

Figure 1: The facial pressure bandage used in the study 
All study subjects were clinically followed up after $48 \mathrm{~h}$ and 7 days post-surgery. During these two follow-up visits, evaluation of postsurgical sequels, i.e. facial swelling and trismus, was completed through re-taking the related clinical measurements, i.e. facial measurements and maximum mouth-opening distance, in exactly the same way as they were performed at the starting point. The facial swelling was calculated as the percentage change in facial measurements compared to the baseline facial measurements. Similarly, trismus was defined as the percentage of negative change in maximum mouth opening from the baseline measurement. During these two follow-up visits, patients were also asked to indicate the pain level on VAS. Sutures were removed on the $7^{\text {th }}$ day per study protocol.

Sample size calculations were performed using G*Power software V3.1 (Univesität Kiel, Germany) and mean values $( \pm S D)$ obtained from a similar study [10]. Statistical tests were performed using Statistical Package for the Social Sciences for Windows V19 (SPSS Inc, Chicago, IL, USA). These included descriptive and comparative tests of variables. Independent $t$-student and Chi-square tests were mainly applied to assess differences in mean values between the test and control groups. Statistical significance was set at $5 \%$.

\section{Results}

After screening 44 patients with bilateral impacted third molars, 21 patients with 42 impacted third molars $(n=42)$ were eligible and included in all phases of this randomized clinical study. Flowchart of the progress through enrollment, allocation, follow-up, and data analysis phases of the study was shown in (Figure 2). Participants' age ranged from 20 to 39 years (mean age of $23.4 \pm 4.4$ years). Females contributed $66.7 \%$ of study participants. The study participants' demographic information and characteristics were summarized in (Table 1).

A total of 42 impacted mandibular third molar surgeries were performed. No statistical difference was existed in terms of surgical durations $(p=0.096$; $p=0.665)$, side $(p=0.538)$, predictable complexity $(p=0.663)$ and difficulty $(p=0.14)$. The included third molars were asymptomatic. All participants reported zero-pain level on the 10-cm VAS at baseline. Crown and/or roots sectioning were not necessary in any of cases. No major complications were associated with the 42 surgical extractions.

Differences in mean pain level scores on VAS between the pressure bandage group and dexamethasone group were statistically insignificant after $48 \mathrm{~h}(p=0.463)$ and 7 days $(p=0.746)$. There was also no significant difference in patients' need

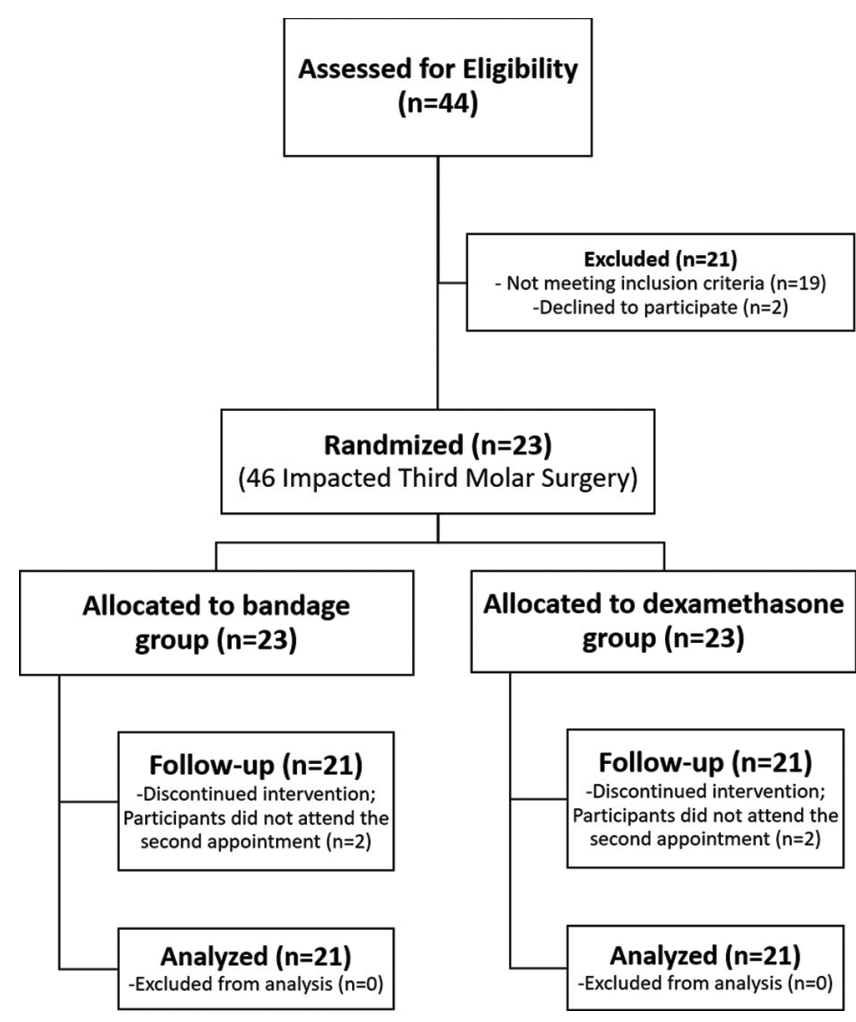

Figure 2: Flow diagram of stages of the split-mouth, randomized, clinical study

for analgesics (assessed by summing the recorded numbers of painkiller intake for 7 days) between the two groups ( $p=0.148$; Table 1$)$.

Table 1: Comparison of patients' characteristics and study variables between pressure bandage group and dexamethasone group, including age, sex, information about surgery and pain, swelling, and trismus assessments (all values were expressed as mean \pm SD except for "gender" and "surgical side" which were expressed as frequency)

\begin{tabular}{|c|c|c|c|c|c|c|}
\hline Variable & \multicolumn{2}{|c|}{$\begin{array}{l}\text { Pressure bandage } \\
\text { group }(n=21) \\
\text { Mean } \pm \text { SD }\end{array}$} & \multicolumn{2}{|c|}{$\begin{array}{l}\text { Dexamethasone } \\
\text { group }(n=21) \\
\text { Mean } \pm \text { SD }\end{array}$} & $\begin{array}{l}\text { Test } \\
\text { value }\end{array}$ & $p$-value \\
\hline Age (year) & 23.38 & \pm 4.40 & $23.38=$ & 4.40 & 0.00 & $1.000^{*}$ \\
\hline \multicolumn{7}{|l|}{$\begin{array}{l}\text { Age (year) } \\
\text { Gender }\end{array}$} \\
\hline Male & 7 & & 7 & & 0.00 & $1.000^{* \star}$ \\
\hline Female & 14 & & 14 & & & \\
\hline \multicolumn{7}{|l|}{ Surgical side } \\
\hline Right & 12 & & 9 & & 0.86 & $0.538^{\star \star}$ \\
\hline Left & 9 & & 12 & & & \\
\hline \multicolumn{7}{|l|}{ Surgical difficulty } \\
\hline Pernambuco index & 9.67 & \pm 0.73 & 9.57 & \pm 0.68 & 0.44 & $0.663^{*}$ \\
\hline VAS $(\mathrm{cm})$ & 3.71 & \pm 0.96 & 3.33 & \pm 0.66 & 1.50 & $0.140^{*}$ \\
\hline \multicolumn{7}{|l|}{ Surgical duration (min) } \\
\hline Total surgery duration & 31.43 & \pm 5.77 & 28.90 & \pm 3.56 & 1.71 & $0.096^{*}$ \\
\hline Bone removal duration & 7.71 & \pm 5.98 & 6.95 & \pm 5.31 & 0.44 & $0.665^{*}$ \\
\hline \multicolumn{7}{|l|}{ Pain assessment } \\
\hline VAS after $48 \mathrm{~h}(\mathrm{~cm})$ & 1.90 & \pm 1.75 & 2.26 & \pm 1.35 & -0.74 & $0.463^{*}$ \\
\hline VAS after 7 days $(\mathrm{cm})$ & 0.83 & \pm 1.21 & 0.71 & \pm 1.16 & 0.33 & $0.746^{*}$ \\
\hline Total Analgesic Intake & 3.33 & \pm 1.93 & 2.43 & \pm 2.04 & 1.48 & $0.148^{\star}$ \\
\hline \multicolumn{7}{|l|}{ Swelling assessment (\%) } \\
\hline Change rate in OC-T after $48 \mathrm{~h}$ & 5.39 & \pm 4.15 & 4.69 & \pm 3.71 & 0.57 & $0.573^{*}$ \\
\hline Change rate in OC-T after 7 days & 2.02 & \pm 3.03 & 1.17 & \pm 1.59 & 1.14 & $0.263^{*}$ \\
\hline Change rate in OC-A after $48 \mathrm{~h}$ & 7.33 & \pm 3.48 & 9.35 & \pm 4.46 & -1.63 & $0.110^{*}$ \\
\hline Change rate in OC-A after 7 days & 1.46 & \pm 1.67 & 2.66 & \pm 2.30 & -1.93 & $0.061^{*}$ \\
\hline \multicolumn{7}{|c|}{ Trismus assessment (\%) } \\
\hline $\begin{array}{l}\text { Change rate in mouth opening } \\
\text { after } 48 \mathrm{~h}\end{array}$ & 26.40 & \pm 12.97 & 27.85 & \pm 12.29 & -0.37 & $0.712^{*}$ \\
\hline $\begin{array}{l}\text { Change rate in mouth opening } \\
\text { after } 7 \text { days }\end{array}$ & 10.69 & \pm 10.10 & 11.85 & \pm 13.68 & -0.31 & $0.756^{*}$ \\
\hline
\end{tabular}

The mean postoperative swelling rates (considering mean rates of change in OC-T and OC-A facial distances) after $48 \mathrm{~h}$ in pressure bandage group 
$(5.39 \pm 4.15 \%$ and $7.33 \pm 3.48 \%$ respectively) were found to be comparable to mean postoperative swelling rates after $48 \mathrm{~h}$ in dexamethasone group (4.69 $\pm 3.71 \%$ and $9.35 \pm 4.46 \%$ ) with no significant differences $(p>0.05)$. After 7 days, similar finding was observed and there were no significant differences in swelling rates between the test and control groups ( $p>0.05$; Table 1).

A similar trend was found in the mean rates of postoperative trismus after $48 \mathrm{~h}$ and 7 days. In the pressure bandage group, mean rates of change in interincisal distance $(26.40 \pm 12.97 \%$ and $10.69 \pm 10.1 \%$ respectively) were comparable to the dexamethasone group $(27.85 \pm 12.29 \%$ and $11.85 \pm 13.68)$ with no significant differences $(p>0.05$; Table 1$)$.

\section{Discussion}

Impacted third molar surgery is a very common procedure that is performed on regular basis in every dental clinic [11]. Postsurgical sequels are frequently occurred disturbing both patients and oral surgeons [2]. These may exaggerate patients' concerns whether to get their impacted molars extracted or not, even when clear extraction indication exists. They mainly include pain, trismus, and most importantly extraoral swelling. Oral and maxillofacial surgeons always try to eliminate or at least to reduce these postsurgical sequels in order to provide their patients with the best quality of treatment.

Many factors can influence postoperative symptoms and complications of impacted third molar surgeries [2]. Extended operative time may increase trauma to both soft and hard tissues leading to increased severity of postsurgical sequels [12]. In the present study, there were no significant differences in total surgical duration nor bone removal duration between the dexamethasone group and facial pressure bandage group $(p>0.05)$. Moreover, the crossover design of the study ensured that almost all subjective influencing factors including age, gender, race, genetic makeup, and pain tolerance, were neutralized by making all study participants receive both the test and control procedures [13]. Study protocol allowed a period of at least 3 weeks between the first and second interventions to ensure that the baseline levels of measured variables were restored. Furthermore, there were no significant differences in impaction angulation, side of surgery, and surgical difficulty between study groups ( $p>0.05$; Table 1).

Multiple protocols were introduced to prevent, reduce and/or manage postsurgical sequels after impacted third molars extractions including pharmaceutical, flap-design-related, and alternative methods [1], [4], [8]. The intra-socket application of platelet-rich fibrin was proposed to minimize the risk of postoperative complications and improve wound healing with mixed outcomes [14]. The effect of topical application of honey on wound healing and postsurgical pain was tested and showed promising outcomes in that regard [3]. The use of piezoelectric technology in third molars surgeries was reported to be beneficial in reducing their postsurgical swelling and pain [12], [15]. However, the aforementioned methods might significantly increase the total surgery duration in a way that might disturb both the patient and the operator [16].

Corticosteroids were proved to be beneficial in reduction of pain, trismus, and swelling after third molar surgeries [5]. Single-dose of dexamethasone $(8 \mathrm{mg})$ was found to effectively reduce these postoperative sequels [17], [18]. Some oral surgeons consider it as a standard keystone in almost every medical prescription in this context. For that reason, intramuscular $8 \mathrm{mg}$ of dexamethasone was chosen for the control group of the present study. Studies showed that it was even superior to NSAIDs like ketorolac after third molar extraction [19]. Nevertheless, short-term corticosteroid use may not always be safe and free of risks in every patient [7]. It may be associated with hypertension, hyperglycemia, pancreatitis, cutaneous, hematologic, and immunologic effects [7]. Therefore, it is of utmost importance to find a risk-free alternative with a similar effectiveness to be used whenever corticosteroids are contraindicated. Hereby, the purpose of this study was to evaluate the effect of compression facial garment on impacted mandibular third molar postsurgical sequels.

In medicine, applying an elastic compression therapy after surgery is a matter of controversy in terms of clinical outcomes improvement [20-23]. Matthews et al. believed that applying such bandage after total knee arthroplasty is neither beneficial nor harmful to the patient [20]. In contrary, Yu et al. concluded that compression dressing was an excellent tool to control edema associated with surgery or trauma of lower extremities [21]. Postoperative short-term compression therapy was found to reduce the severity of pain and edema after endovenous laser ablation treatment [22]. Ristow et al. found that elastic therapeutic tape application after open reduction and internal fixation of mandibular fractures was cost-effective in decreasing the postsurgical swelling [23].

Based on the results of this study, there were no significant differences $(P>0.05)$ in the clinical outcomes of surgical extraction of impacted mandibular third molars in terms of post-surgical swelling, pain, and trismus whether facial compression bandage was applied, or intramuscular dexamethasone $8 \mathrm{mg}$ was injected after extraction. It seems that this compression bandage therapy has akin effect, compared to dexamethasone, on these postoperative sequels. The findings of the present study were in line with Ghavimi et al. study results [10]. They concluded that pressure bandage, made with roll of gauze following the Barton method, was effective in reducing pain and swelling after mandibular third molar surgery [10]. 
However, the ready-made facial garment used in this study may be applied much easier and considered less time-consuming.

It is known that compression therapy is most effective when associated with movement [24]. For this reason, participants were asked to do mandibular exercises, namely gentle lateral and vertical mandibular movements, multiple times during the first postoperative $48 \mathrm{~h}$. In this manner, a massaging effect may be exerted to the patient's face. Special weaving technique used in designing the applied bandage may also cause micromassage effects during head movements (Figure 1). Gentle message techniques can improve lymph flow, stimulate microcirculation and reduce pain and edema [25].

The study, however, has some limitations. First, the crossover design of this study may increase potential dropouts. Two participants, who only completed the first intervention and did not continue to the second one, were excluded (Figure 2). Second, some patients had style-related concerns regarding wearing the facial garment. However, most patients preferred to wear facial compression bandage and not to get intramuscular injections. Finally, the tested compression bandage is originally used for the chin-neck region, so we had to make some methodological modifications in order to suit the new use. Square pieces of gauze were placed under the bandage at the mandibular angle to obtain adequate compression on the surgical site.

\section{Conclusion}

The present study showed that compression therapy via facial pressure bandage seems as effective as systemic single dose of dexamethasone $(8 \mathrm{mg})$ in terms of postoperative pain, trismus, and swelling after mandibular third molar impaction surgery.

\section{Acknowledgment}

The authors would like to thank Dr. Dunia Taha for her great assistance at different stages of the study.

\section{References}

1. Mawardi H, Ghazalh S, Shehatah A, Abdelwahid A, Aljohani A, Felemban $O$, et al. Systemic use of arnica Montana for the reduction of postsurgical sequels following extraction of impacted mandibular $3^{\text {rd }}$ molars: A pilot study. Evid Based
Complement Alternat Med. 2020;2020:6725175. https://doi. org/10.1155/2020/6725175

2. Kim JC, Choi SS, Wang SJ, Kim SG. Minor complications after mandibular third molar surgery: Type, incidence, and possible prevention. Oral Surg Oral Med Oral Pathol Oral Radiol Endod. 2006;102(2):e4-11. https://doi.org/10.1016/j.tripleo.2005.10.050 PMid:16876044

3. Al-Khanati NM, Al-Moudallal Y. Effect of intrasocket application of manuka honey on postsurgical pain of impacted mandibular third molars surgery: Split-mouth randomized controlled trial. J Maxillofac Oral Surg. 2019;18(1):147-52. https://doi. org/10.1007/s12663-018-1142-z

PMid:30728706

4. Tiigimae-Saar J, Leibur E, Tamme T. The effect of prednisolone on reduction of complaints after impacted third molar removal. Stomatologija. 2010;12(1):17-22.

PMid:20440092

5. Ngeow WC, Lim D. Do corticosteroids still have a role in the management of third molar surgery? Adv Ther. 2016;33(7):110539. https://doi.org/10.1007/s12325-016-0357-y

PMid:27287853

6. Harirforoosh S, Asghar W, Jamali F. Adverse effects of nonsteroidal antiinflammatory drugs: An update of gastrointestinal, cardiovascular and renal complications. J Pharm Pharm Sci. 2013;16(5):821-47. https://doi. org/10.18433/j3vw2f

PMid:24393558

7. Buchman AL. Side effects of corticosteroid therapy. J Clin Gastroenterol. 2001;33(4):289-94.

PMid: 11588541

8. Hassan B, Al-Khanati NM, Bahhah H. Effect of lingual-based flap design on postoperative pain of impacted mandibular third molar surgery: Split-mouth randomized clinical trial. Med Oral Patol Oral Cir Bucal. 2020;25(5):e660-7. https://doi.org/10.4317/ medoral.23666

PMid:32683384

9. de Carvalho RW, Vasconcelos BC. Pernambuco index: Predictability of the complexity of surgery for impacted lower third molars. Int J Oral Maxillofac Surg. 2018;47(2):234-40. https://doi.org/10.1016/j.ijom.2017.07.013 PMid:28818641

10. Ghavimi MA, Arta A, Zadeh AG, Hashemi M, Yazdeni J, Mohammadi $\mathrm{SH}$. The effect of the pressure bandage use in varying the pain and swelling after lower third molar surgery. Int J Curr Res Aca Rev. 2014;2(9):135-40.

11. Cunha-Cruz J, Rothen $M$, Spiekerman $C$, Drangsholt $M$, McClellan L, Huang GJ, Northwest Practice-Based Research Collaborative in Evidence-Based Dentistry. Recommendations for third molar removal: A practice-based cohort study. Am J Public Health. 2014;104(4):735-43. https://doi.org/10.2105/ ajph.2013.301652 PMid:24524519

12. Patil C, Jadhav A, Rajanikanth K, Bhola N, Borle RM, Mishra A Piezosurgery vs bur in impacted mandibular third molar surgery: Evaluation of postoperative sequelae. J Oral Biol Craniofac Res. 2019;9(3):259-62. https://doi.org/10.1016/j.jobcr.2019.06.007 PMid:31249772

13. Sulaiman F, Al-Khanati NM, Brad B, Jumaa R. Evaluating glycemic response to lidocaine with two different vasoconstrictors in diabetic patients undergoing tooth extraction: Crossover randomized clinical study. Int J Pharm Res. 2021;13(1):702-6. https://doi.org/10.31838/ijpr/2021.13.01.122

14. Xiang X, Shi P, Zhang P, Shen J, Kang J. Impact of platelet-rich fibrin on mandibular third molar surgery recovery: A systematic review and meta-analysis. BMC Oral Health. 2019;19(1):163. 
https://doi.org/10.1186/s12903-019-0824-3

PMid:31345203

15. Bhati B, Kukreja P, Kumar S, Rathi VC, Singh K, Bansal S Piezosurgery versus rotatory osteotomy in mandibular impacted third molar extraction. Ann Maxillofac Surg. 2017;7(1):5-10.

PMid:28713729

16. Cicciù M, Stacchi C, Fiorillo L, Cervino G, Troiano G, Vercellotti T, et al. Piezoelectric bone surgery for impacted lower third molar extraction compared with conventional rotary instruments: A systematic review, meta-analysis, and trial sequential analysis. Int J Oral Maxillofac Surg. 2021;50(1):121-31. https:// doi.org/10.1016/j.ijom.2020.03.008

PMid:32284166

17. Klongnoi B, Kaewpradub $\mathrm{P}$, Boonsiriseth $\mathrm{K}$, Wongsirichat $\mathrm{N}$. Effect of single dose preoperative intramuscular dexamethasone injection on lower impacted third molar surgery. Int $\mathrm{J}$ Oral Maxillofac Surg. 2012;41(3):376-9. https://doi.org/10.1016/j. ijom.2011.12.014

PMid:22209181

18. Latt MM, Kiattavorncharoen S, Boonsiriseth K, Pairuchvej V, Wongsirichat $\mathrm{N}$. The efficacy of dexamethasone injection on postoperative pain in lower third molar surgery. J Dent Anesth Pain Med. 2016;16(2):95-102. https://doi.org/10.17245/ jdapm.2016.16.2.95 PMid:28879301

19. Martins-de-Barros AV, Barros AM, Siqueira AK, Lucena EE, Sette de Souza $\mathrm{PH}$, Araújo FA. Is dexamethasone superior to Ketorolac in reducing pain, swelling and trismus following mandibular third molar removal? A split mouth triple-blind randomized clinical trial. Med Oral Patol Oral Cir Bucal. 2021;26(2):e141-50. https://doi.org/10.4317/medoral.24088

\section{PMid:33247572}

20. Matthews $\mathrm{CN}$, Chen $\mathrm{AF}$, Daryoush $\mathrm{T}$, Rothman $\mathrm{RH}$ Maltenfort MG, Hozack WJ. Does an elastic compression bandage provide any benefit after primary TKA? Clin Orthop Relat Res. 2019;477(1):134-44. https://doi.org/10.1097/ corr.0000000000000459

PMid:30794237

21. Yu GV, Schubert EK, Khoury WE. The Jones compression bandage. Review and clinical applications. J Am Podiatr Med Assoc. 2002;92(4):221-31.

PMid:11961089

22. Ye K, Wang R, Qin J, Yang X, Yin M, Liu X, et al. Post-operative benefit of compression therapy after endovenous laser ablation for uncomplicated varicose veins: A randomised clinical trial. Eur J Vasc Endovasc Surg. 2016;52(6):847-53. https://doi. org/10.1016/j.ejvs.2016.09.005

PMid:27760697

23. Ristow O, Hohlweg-Majert B, Kehl V, Koerdt S, Hahnefeld L, Pautke C. Does elastic therapeutic tape reduce postoperative swelling, pain, and trismus after open reduction and internal fixation of mandibular fractures? J Oral Maxillofac Surg. 2013;71(8):1387-96. https://doi.org/10.1016/j.joms.2013.03.020 PMid:23676774

24. Partsch H. Compression therapy: Clinical and experimental evidence. Ann Vasc Dis. 2012;5(4):416-22.

PMid:23641263

25. Szolnoky G, Szendi-Horváth K, Seres L, Boda K, Kemény L. Manual lymph drainage efficiently reduces postoperative facial swelling and discomfort after removal of impacted third molars. Lymphology. 2007;40(3):138-42.

PMid:18062616 